\title{
Exposure to cold and draught, alcohol consumption, and the NS-phenotype are associated with chronic bronchitis: an epidemiological investigation of 3387 men aged 53-75 years: the Copenhagen Male Study
}

\author{
P Suadicani, H O Hein, H W Meyer, F Gyntelberg
}

\begin{abstract}
Objectives-This study was performed to estimate the strength of association between chronic bronchitis and lifetime exposure to occupational factors, current lifestyle, and the NS-phenotype in the MNS blood group among middle aged and elderly men.

Methods-The study was carried out within the frameworks of the Copenhagen Male Study. Of 3387 men 3331 men with a mean age of 63 (range 53-75) years could be classified by prevalence of chronic bronchitis. As well as the completion of a large questionnaire on health, lifestyle, and working conditions, all participants had a thorough examination, including measurements of height and weight and blood pressure and a venous blood sample was taken for the measurement of serum cotinine and MNS typing; $16.5 \%$ of the men had the NS-phenotype. Chronic bronchitis was defined as cough and phlegm lasting 3 months or more for at least 2 years; $14.6 \%$ had chronic bronchitis.
\end{abstract}

Results-Smoking and smoke inhalation were the factors most strongly associated with prevalence of chronic bronchitis. There were three major new findings: $(a)$ long term ( $>5$ years) occupational exposure to cold and draught was associated with a significantly increased prevalence of chronic bronchitis; compared with others, and adjusted for confounders, the odds ratio (OR) with $95 \%$ confidence interval (95\% CI) was 1.4 (1.1 to 1.7$)$, $\mathbf{p}=0.004$; (b) a significant $\mathrm{J}$ shaped association existed between alcohol use and bronchitis, $p<0.001$, with the lowest prevalence found among moderate users; (c) a significant gene by environment association existed between smoking and the NS-phenotype in the MNS blood group; only among smokers was the NSphenotype associated with a significantly decreased risk of chronic bronchitis, OR $0.67(0.47-0.97), p=0.02$. Other well known associations between dust, fumes, and even exposure to solvents and bronchitis were confirmed.

Conclusion-The results emphasise the multifactorial nature of chronic bronchitis, and show some hitherto unrecognised associations between cold and draught exposure, alcohol consumption, and the NS-phenotype and chronic bronchitis. (Occup Environ Med 2001;58:160-164)

Keywords: alcohol; chronic bronchitis; cold; draught; genetic marker; MNS; occupational exposure

Based on results from studies of non-selected populations $^{1-7}$ and occupational cohorts, ${ }^{8-11}$ it has been established that smoking, exposure to dust, and exposure to fumes and solvents are associated with risk of chronic bronchitis; the literature on lifestyle factors and environmental exposures has been reviewed by Higgins ${ }^{12}$ and by Garshick et al. ${ }^{13}$

Genetic factors also have been implicated in the aetiology of chronic bronchitis. In a recent review article, Sandford et al stated that only a few genes have been investigated as potential risk factors for chronic bronchitis. ${ }^{5}$ Homozygosity for the $Z$ allele of the $\alpha 1$-antitrypsin gene has been established as a risk factor, and heterozygotes for the $\mathrm{Z}$ allele may be at increased risk. Other mutations affecting the structure of $\alpha 1$-antitrypsin or the regulation of gene expression have been identified as risk factors. Genes, including those for $\alpha 1$ antichymotrypsin, $\alpha 2$-macroglobulin, vitamin $\mathrm{D}$ binding protein, and blood group antigens have been associated with the development of bronchitis-for example, in the Copenhagen Male Study. ${ }^{14}$ Among more than 3000 middle aged and elderly men there was a significant, heterogenous association between the MNS phenotypes and prevalence of chronic bronchitis, with the lowest prevalence found in men with the NS-phenotype.

The strength of the association between lifestyle and environmental factors and chronic bronchitis may depend on genetics. Despite this, the importance of the interplay of genetic and environmental factors has not, to our knowledge, previously been studied in nonselected populations. This study of middle aged and elderly men was performed to $(a)$ estimate the relative strength of association between chronic bronchitis and occupational and lifestyle factors and the NS-phenotype; and, $(b)$ to test if the risk associated with identified occupational and lifestyle factors was modified by the NS-phenotype. 
Table 1 Genetic, lifestyle, clinical, and sociodemographic characteristics of men with and without chronic bronchitis

\begin{tabular}{|c|c|c|c|}
\hline & $\begin{array}{l}\text { Bronchitis } \\
n=485\end{array}$ & $\begin{array}{l}\text { No bronchitis } \\
n=2846\end{array}$ & $p$ Value \\
\hline \multicolumn{4}{|l|}{ NS-phenotype in MNS blood group: } \\
\hline Overall (\%) & 13.6 & 17.0 & 0.073 \\
\hline Among smokers (\%) & 12.7 & 17.4 & 0.033 \\
\hline \multicolumn{4}{|l|}{ Lifestyle factors: } \\
\hline \multicolumn{4}{|l|}{ Alcohol use: } \\
\hline Abstention (\%) & 12 & 11 & 0.532 \\
\hline Moderate (1-21 drinks/week) (\%) & 51 & 60 & $<0.001$ \\
\hline More than moderate (22-35 drinks/week) (\%) & 21 & 19 & 0.145 \\
\hline Heavy use ( $>35$ drinks/day) $(\%)$ & 16 & 10 & $<0.001$ \\
\hline Low physical activity, <4 h/week (\%) & 52 & 47 & 0.088 \\
\hline Smoking $(\%)$ & 80 & 51 & $<0.001$ \\
\hline \multicolumn{4}{|l|}{ Smokers only: } \\
\hline Inhalation $(\%)$ & 82 & 72 & $<0.001$ \\
\hline Amount smoked (g/day) & $17.2(8.0)$ & $14.9(7.8)$ & $<0.001$ \\
\hline \multicolumn{4}{|l|}{ Clinical or paraclinical variables: } \\
\hline Peak flow $(1 / \mathrm{min})$ & $412(125)$ & $504(87)$ & $<0.001$ \\
\hline Height $(\mathrm{cm})$ & $173(6)$ & $174(6)$ & $<0.001$ \\
\hline Weight $(\mathrm{kg})$ & $76(12)$ & $78(11)$ & 0.009 \\
\hline Systolic BP (mm Hg) & $118(16)$ & $122(17)$ & $<0.001$ \\
\hline Diastolic BP (mm Hg) & $71(13)$ & $73(12)$ & $<0.001$ \\
\hline Serum cotinine $(\mathrm{ng} / \mathrm{ml})$ & $327(227)$ & $197(234)$ & $<0.001$ \\
\hline \multicolumn{4}{|l|}{ Smokers only: } \\
\hline Serum cotinine $(\mathrm{ng} / \mathrm{ml})$ & $392(194)$ & $343(201)$ & $<0.001$ \\
\hline \multicolumn{4}{|l|}{ Other characteristics: } \\
\hline Low social class (classes IV and V) (\%) & 59 & 51 & $<0.001$ \\
\hline Retired (\%) & 54 & 47.5 & 0.003 \\
\hline Age $(y$, mean $(S D))$ & $63.2(5.2)$ & $62.8(5.2)$ & 0.175 \\
\hline
\end{tabular}

Values are means (SD) or frequencies (\%). p Values are of Student's $t$ test (for continuous variables other than peak flow), Mann-Whitney rank sum analysis (for peak flow), or Yates corrected $\chi^{2}$ analysis (for categorical variables).

\section{Subjects and methods}

The Copenhagen Male Study ${ }^{15}$ was set up in 1970 as a prospective cardiovascular cohort study of 5249 men with a mean age of 48 years (range 40-59). In 1985-6 a new baseline was established. All survivors from the 1970 study were traced through the Danish Central Population Register. Between June 1985 and June 1986 all survivors (except 34 emigrants) from the original cohort were invited to take part in this study: $3387(75 \%)$ agreed and gave informed consent. Their mean age was 63 (range 53-74) years.

The 1985-6 study took place at Glostrup Hospital, University of Copenhagen. Each subject was interviewed (by $\mathrm{HOH}$ ) about a previously completed questionnaire and then had a clinical examination.

QUESTIONNAIRE INFORMATION

Several questions were asked on previous occupational exposure. Each question on exposure was phrased "Have you been exposed often-that is, several times a week-to exposure at your current or former jobs?." The answer options were yes, no, and, if yes, for how

Table 2 Relative strength of association with chronic bronchitis of genetic, lifestyle, clinical, and sociodemographic characteristics

\begin{tabular}{lll}
\hline & OR (95\% CI) & p Value \\
\hline Smoking $v$ not & $2.5(1.8$ to 3.4$)$ & $<0.001$ \\
Inhalation $v$ not & $1.7(1.3$ to 2.3$)$ & $<0.001$ \\
Alcohol use, different categories referencing abstainers: & $0.8(0.6$ to 1.1$)$ & $<0.001$ \\
$\quad$ Moderate use $(1-21$ drinks/week): & $1.1(0.7$ to 1.6$)$ & \\
$\quad$ More than moderate (22-35 drinks/week): & $1.4(0.95$ to 2.1$)$ & \\
$\quad$ Heavy use ( $>35$ drinks/week): & $1.4(1.1$ to 1.7$)$ & 0.002 \\
Retired $v$ not & $0.99(0.98$ to 0.997$)$ & 0.002 \\
Systolic blood pressure (mm Hg, risk associated with a one & & \\
$\quad$ unit change) & $0.98(0.96$ to 0.99$)$ & 0.004 \\
Height (cm, risk associated with a one unit change) & $0.7(0.6$ to 0.99$)$ & 0.038 \\
NS-phenotype $v$ others & & \\
\hline
\end{tabular}

Not in the final model $(p>0.10)$ : social class, weight, age.

Variables are ordered according to statistical strength of association with bronchitis after multivariate adjustment in a logistic regression model with backward elimination of variables. many years? For most analytical purposes occupational exposures were dichotomised at more than 5 years of exposure.

Based on a slightly modified version of the British Medical Research Council questionnaire on respiratory symptoms ${ }^{16}$ the men were classified as having chronic bronchitis or not. Chronic bronchitis was defined as cough and phlegm lasting 3 months or more for at least 2 years. Of 3331 participants with useful questionnaire information on relevant items, 485 $(14.6 \%)$ were classified as having chronic bronchitis.

Total weekly alcohol consumption was calculated from items about average alcohol consumption on weekdays and at weekends. Intakes of beer, wine, and spirits were reported separately, and most of the alcohol consumed was beer. One drink corresponded to about $12 \mathrm{~g}$ ethanol. The men classified themselves as never smokers, previous smokers, or current smokers. Current tobacco consumption was calculated from information about the number of cigarettes, cheroots, cigars, or the weight of pipe tobacco smoked daily. One cigarette was taken as equivalent to $1 \mathrm{~g}$ tobacco, one cheroot as $3 \mathrm{~g}$ tobacco, and one cigar as $4 \mathrm{~g}$ tobacco. To validate the tobacco information serum cotinine was measured with a radioimmunoassay (RIA) method at Medi-Lab, Copenhagen. As previously estimated by means of measurements of serum cotinine, the validity of tobacco reporting was high. ${ }^{17}$ The men classified themselves for leisure time physical activity as either sedentary, slightly active-less than 2 hours a week-or physically more active.

\section{CLINICAL EXAMINATION}

A clinical examination included measurement of peak expiratory flow with a WrightMcKerrow peak flow meter, and measurements of height, weight, and blood pressure; blood pressure was measured on the right arm with the subject seated, by means of the manometer developed by the London School of Hygiene..$^{18}$ A venous blood sample was taken for MNS typing and measurements of cotinine concentrations after the subject had fasted for at least 12 hours. The typing was carried out on red cells with conventional haemagglutination techniques; $16.5 \%$ of the men had the NS-phenotype.

SOCIAL CLASS

The men were classified into five social classes based on a modification of the system of Svalastoga, ${ }^{19}$ which involved level of education and job profile. ${ }^{20}$ Strata were defined as follows: class I, self employed subjects with at least 21 employees, white collar workers with at least 51 subordinates, or subjects with an academic degree; class II, self employed subjects with 6-20 employees, white collar workers with 11-50 subordinates, or subjects with an intermediate education; class III, self employed subjects with 1-5 employees and white collar workers with 1-10 subordinates; class IV, self employed subjects without employees, white collar workers without subordinates or without qualified work, and skilled blue collar workers; 
Table 3 Association between chronic bronchitis and relevant occupational long term exposure $(>5 y)$ to physical and chemical factors

\begin{tabular}{lllr}
\hline Exposure & $\begin{array}{l}\text { Chronic bronchitis } \\
n=485(\%)\end{array}$ & $\begin{array}{l}\text { No bronchitis } \\
n=2846(\%)\end{array}$ & p Value \\
\hline Cold and draught & 60 & 49 & $<0.001$ \\
Strong variations of temperature & 40 & 31 & $<0.001$ \\
Strong heat & 15 & 11 & 0.024 \\
Moist and humidity & 14 & 10 & 0.010 \\
Dust (concrete, granite, etc) & 13 & 8 & $<0.001$ \\
Asbestos & 7 & 4 & 0.004 \\
Soldering fumes & 10 & 9 & 0.447 \\
Welding fumes & 13 & 9 & 0.020 \\
Organic solvents & 16 & 10 & 0.001 \\
Vapours from lacquer, paint, varnish & 8 & 6 & 0.125 \\
Plastic (manufacture of or exposure to vapours) & 2.7 & 1.1 & 0.145 \\
Glass fibre & 2.5 & 1.6 &
\end{tabular}

p Values are of Yates's corrected $\chi^{2}$ tests. Variables are presented according to their order in the questionnaire.

class V, unskilled blue collar workers. Typical jobs in the study cohort were; in social class I officer, civil engineer, office executive, head of department; social class II head clerk, engineer, non-academic architect; social class III engine driver, train guard; social class IV machine fitter in a telephone company, station foreman; social class $\mathrm{V}$ unskilled labourer, mechanic, or driver. For presentation purposes social class was divided into two groups: low social class (classes IV and V) and high social class (classes I, II, and III).

\section{ETHICS}

Each participant was informed that all personal data were confidential, and gave written consent about participation. The study was approved by the ethics committee for medical research in the County of Copenhagen.

\section{STATISTICS}

Basic analyses comprising Student's $t$ test, $\chi^{2}$ analyses, and the regression analyses, were performed with the SPSS statistical software for Windows. ${ }^{21}{ }^{22}$ Odds ratios were calculated by taking the natural $\log _{e}$ raised to the regression coefficient for the variable of interest in a multiple logistic regression model with stepwise backward elimination of variables and the maximum likelihood ratio method. ${ }^{23}$ Whether a forward stepwise, a backward stepwise, or a forced entry approach was used, did not materially change the association between covariates and the prevalence of chronic bronchitis. Multiplicative interaction terms between groups of genetic risk and lifestyle, occupational exposures, and clinical characteristics, were included in a final analysis to test whether the risk associated with identified lifestyle and other factors was modified by genetic factors. The rationale of the method has been de-

Table 4 Relative strength of association between chronic bronchitis and long term occupational exposure to physical and chemical factors adjusted for social class and age

\begin{tabular}{lll}
\hline & OR $(95 \%$ CI $)$ & $p$ Value \\
\hline Cold and draught exposure $v$ not & $1.4(1.1$ to 1.7$)$ & 0.002 \\
Dust exposure $v$ not & $1.5(1.1$ to 2.0$)$ & 0.020 \\
Social class IV/V $v$ I, II, III & $1.2(0.99$ to 1.5$)$ & 0.063 \\
Organic solvent exposure $v$ not & $1.3(0.99$ to 1.8$)$ & 0.066 \\
\hline
\end{tabular}

Not in the final model ( $p>0.10$ ): age, plastic (manufacture of or exposure to vapours), strong variations of temperature, strong heat, moist and humidity, asbestos, soldering fumes, welding fumes, vapours (from lacquer, paint, and varnish), glass fibre.

Variables are ordered according to strength of association with bronchitis after multivariate adjustment in a logistic regression model with backward elimination of variables. scribed by Kleinbaum et al. ${ }^{24}$ All risk factor covariates in the regression analyses were those measured in 1985-6. In the multivariate analyses we used the program default allowing variables with $\mathrm{p}$ values $\leqslant 0.10$ to remain in the adjusted model.

\section{Results}

Table 1 shows the distribution of genetic, clinical, and sociodemographic characteristics in men with and without chronic bronchitis. Apart from lower peak flow values in men with bronchitis, the most pronounced differences were found for smoking, but also alcohol consumption was associated with the prevalence of bronchitis; moderate consumption had a lower prevalence and heavy consumption had a higher prevalence of chronic bronchitis. Men with bronchitis were less physically active, belonged to lower social classes, and were more often retired. The NS-phenotype was more often present in men without bronchitis, with a significantly stronger association among smokers. Moreover, men with bronchitis were of shorter stature, had a lower blood pressure, and weighed less than men without bronchitis.

Table 2 shows the results of a multivariate analysis including relevant factors presented in table 1. Positively associated with chronic bronchitis were current smoking, smoke inhalation, and being retired; negative associations were found with blood pressure, height, and the NS-phenotype, and a J shaped association was found with alcohol consumption. Social class, weight, and age were not in the final model.

Table 3 shows the association between potentially relevant occupational long term exposures to physical and chemical factors and prevalence of chronic bronchitis. All the listed factors were more prevalent among men with bronchitis. The factors were either of a climatic nature or related to exposure to dust, fumes, and organic solvents.

The relative strength of association between chronic bronchitis and long term occupational exposure to physical and chemical factors after multivariate analysis is shown in table 4 . The strongest factor was long term exposure to cold and draughts, but also exposure to organic solvents and dust remained in the statistical model even when adjustment was made for social class. The odds ratios of occupational exposures associated with bronchitis in the adjusted multivariate model ranged between 1.3 and 1.5 .

Table 5 shows the relative strength of association between chronic bronchitis and relevant genetic, lifestyle, clinical, and sociodemographic characteristics, and relevant occupational exposures after adjustment in the multivariate model. Smoking and smoke inhalation were the strongest discriminatory factors, but occupational exposure to cold and draught, organic solvents and dust, and the NS-phenotype were also significant covariates of bronchitis. Other factors significantly characterising subjects with chronic bronchitis were blood pressure, age, height, and alcohol consumption. With the same factors as covari- 
Table 5 Relative strength of association with chronic bronchitis of relevant genetic, lifestyle, clinical, sociodemographic characteristics, and relevant occupational exposures

\begin{tabular}{lll}
\hline & OR (95\% CI) & $p$ Value \\
\hline Smoking $v$ not & $2.4(1.7$ to 3.4$)$ & $<0.001$ \\
Inhalation $v$ not & $1.7(1.3$ to 2.4$)$ & $<0.001$ \\
Age (y, risk associated with a one unit change) & $1.04(1.02$ to 1.06$)$ & 0.002 \\
Alcohol use, different categories referencing abstainers: & & 0.003 \\
$\quad$ Moderate use (1-21 drinks/week) & $0.8(0.6$ to 1.1$)$ & 0.003 \\
$\quad$ More than moderate (22-35 drinks/week) & $1.1(0.7$ to 1.6$)$ & 0.004 \\
$\quad$ Heavy use (>35 drinks/week) & $1.5(0.96$ to 2.2$)$ & 0.008 \\
Systolic blood pressure (mm Hg, risk associated with a one & $0.99(0.98$ to 0.997$)$ & 0.019 \\
$\quad$ unit change) & $1.4(1.1$ to 1.7$)$ & 0.025 \\
Long term exposure to cold and draught exposure $v$ not & $1.5(1.1$ to 2.1$)$ & 0.044 \\
Long term exposure to organic solvents $v$ not & $0.98(0.96$ to 0.997$)$ & $1.5(1.1$ to 2.1$)$ \\
Height (cm, risk associated with a one unit change) & $0.7(0.5$ to 0.999$)$ & \\
Long term dust exposure $v$ not & & \\
NS-phenotype $v$ others & & \\
\hline
\end{tabular}

Not in the final model $(\mathrm{p}>0.10)$ : weight, retirement status, social class.

Variables are ordered according to strength of association with bronchitis after multivariate adjustment in a logistic regression model with backward elimination of variables.

ates in analysis of smokers only, compared with men with other phenotypes, the odds ratio (95\% confidence interval) of men with the NS-phenotype was 0.67 (0.47 to 0.97$), \mathrm{p}=0.02$ (not shown in table 5).

In an additional multivariate analysis we included the same factors as in table 5 together with interaction terms (between NS-phenotype and the other factors which remained in the final model in table 5 (not shown)). Of interaction terms, only the interaction between NS-phenotype and smoking was significantly

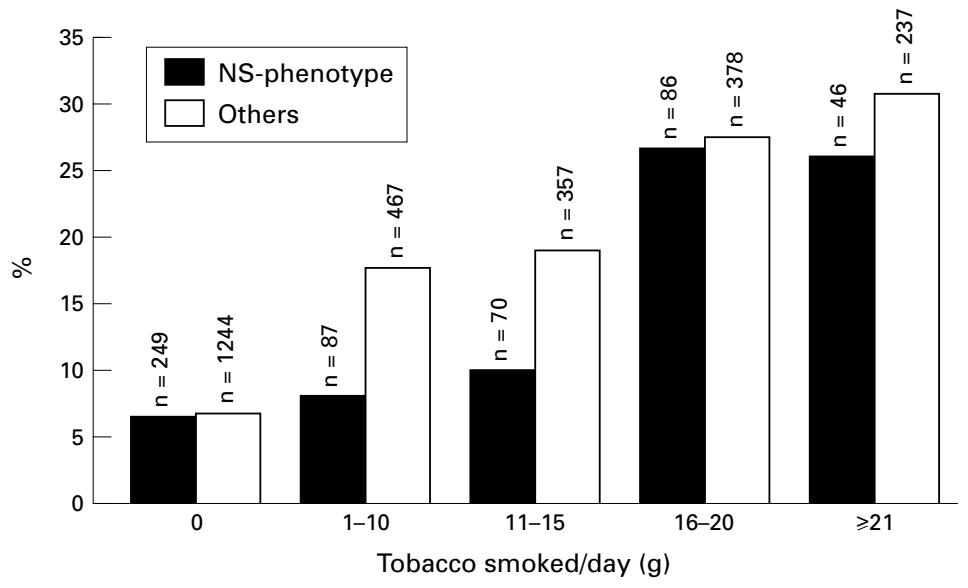

Figure 1 Prevalence of chronic bronchitis by MNS phenotype and amount of tobacco smoked/day.

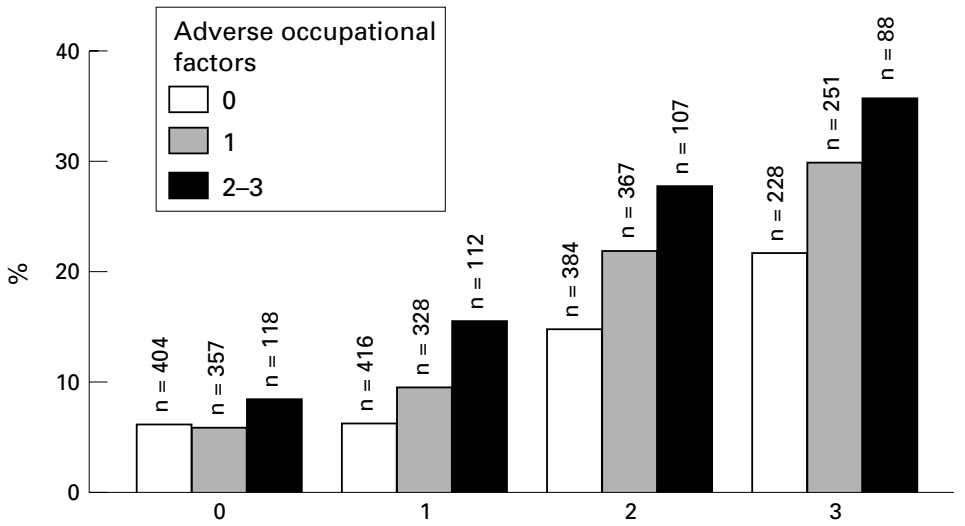

Adverse life style factors (n)

Figure 2 Prevalence of chronic bronchitis by number of adverse lifestyle factors (not moderate alcohol use, smoking, inhalation) and adverse occupational factors (long term exposure to cold and draught, dust, organic solvents). associated with bronchitis, $\mathrm{p}=0.02$. The interplay of the NS-phenotype, current smoking, and prevalence of chronic bronchitis is shown in figure 1.

Figure 2 depicts the interplay of lifestyle factors, occupational exposures, and prevalence of chronic bronchitis; occupational factors were positively associated with the prevalence of chronic bronchitis irrespective of the number of adverse lifestyle factors characterising the group.

\section{Discussion}

This study showed that occupational, lifestyle, and genetic factors were independently associated with chronic bronchitis. There were three major new findings: (a) an increased prevalence of bronchitis among men who had been occupationally exposed to cold and draught for more than 5 years, $(b)$ a J shaped association between alcohol consumption and prevalence of chronic bronchitis, and (c) a significant gene by environment association between smoking and the NS-phenotype in the MNS blood group. Established and less established independent associations between smoking, exposure to dust, and exposure to solvents and chronic bronchitis were confirmed, as were the well known inverse associations between systemic arterial blood pressure and height and chronic bronchitis. ${ }^{25} 26$

In cross sectional studies with retrospective data it is necessary to consider potential bias, in particular bias related to measurements, inadequate confounder control, and selection. Would such sources of bias be able to explain the associations found?

Definition of chronic bronchitis was based on conventional criteria of the British Medical Research Council questionnaire for determining bronchitis. Recognised laboratory methods were used to ascertain genetic markers, and the distribution of MNS phenotypes was in agreement with previous studies on Danes. ${ }^{27}$ Information on smoking was validated by measuring serum cotinine. Data on occupational exposure were based on self assessment. However, previous studies in the Copenhagen Male Study have shown a strong agreement between job titles and exposures likely to be associated with specific job functions. ${ }^{28}$ Despite this, impreci- 
sion in the validity of exposure and outcome variables, and of potential confounders, cannot be excluded. It seems unlikely that this would be responsible for our findings, rather the strength of the associations found may have been underestimated. Selection bias is another potential problem. Chronic bronchitis is no rare cause of death, and severe bronchitis may further handicap a potential study participant, so that he would be less likely to attend the study. Measurement bias seems unlikely, but selection bias could not have been responsible for our findings, as selection phenomena would tend to obscure genuine associations. Finally, a comprehensive confounder control was carried out, so that inadequate control for the impact of major confounders also seems an unlikely explanation for our findings.

Are the new findings biologically plausible? Chronic bronchitis is primarily an inflammatory condition involving various immune responses. As reviewed by Shephard ${ }^{29}$ exposure to various environmental stressors, including cold, may impair the human response to infections by modifying various components of immune function such as $\mathrm{T}$ cell count, natural killer cell counts, cytolytic activity, cytokine secretion, lymphocyte proliferation, and immunoglobulin concentrations. An immunological mechanism caused by exposure to cold and draught therefore seems likely.

An immunological mechanism related to the MNS blood group is also likely. The MNS phenotypes are involved in the function of immunoglobulins, ${ }^{30}$ and is therefore at least one biologically plausible mechanism for the association found between the NS-phenotype blood group and chronic bronchitis. The finding is furthermore interesting in the light of findings made in the field of carcinogenesis that individual susceptibility to carcinogens may be particularly important at low environmental exposures. ${ }^{31}$ This agrees with the finding that, in this study, the apparently protective effect of the NS-phenotype vanished at high exposures to tobacco.

The J shaped association between alcohol consumption and bronchitis is interesting in the light of the well known association between bronchitis and risk of ischaemic heart disease, and the well known $\mathrm{J}$ or $\mathrm{U}$ shaped association between alcohol consumption and risk of ischaemic heart disease. ${ }^{32}$ Previous studies on lung function and haemostatic factors have shown an increased concentration of plasma fibrinogen in subjects with bronchitis, and one of the mechanisms whereby alcohol is supposed to lower risk of heart disease is through its lowering of fibrinogen. ${ }^{33}$

In conclusion, the results of this study emphasise the multifactorial nature of chronic bronchitis, and show some hitherto unrecognised associations between exposure to cold and draughts, alcohol consumption, and the NS-phenotype and chronic bronchitis.

1 Cohen BH, Ball WC Jr, Brashears S, et al. Risk factors in chronic obstructive pulmonary disease (COPD). Am $\mathcal{F}$ Epidemiol 1977;105:223-32.
2 Korn RJ, Dockery DW, Speizer FE, et al. Occupational exposures and chronic respiratory symptoms. A
population-based study. Am Rev Respir Dis 1987;136:298304 .

3 Heederik D, Kromhout H, Burema J, et al. Occupational exposure and 25 year incidence rate of non-specific lung disease: the Zutphen study. Int $\mathcal{F}$ Epidemiol 1990;19:94552.

4 Nejiari C, Tessier JF, Letenneur L, et al. Determinants of chronic bronchitis prevalence in an elderly sample from south-west of France. Monaldi Arch Chest Dis 1996;51:3739.

5 Sandford AJ, Weir TD, Pare PD. Genetic risk factors for chronic obstructive pulmonary disease. Eur Respir $\mathcal{F}$ 1997;10:1380-91.

6 Turkeltaub PC, Gergen PJ. Prevalence of upper and lower respiratory conditions in the US population by social and environmental factors: data from the second National Health and Nutrition Examination Survey, 1976-80 (NHANES II). Ann Allergy 1991;67:147-54.

7 Fishwick D, Bradshaw LM, D'Souza W, et al. Chronic bronchitis, shortness of breath, and airway obstruction by occupation in New Zealand. Am 7 Respir Crit Care Med pation in New Zea

8 Raaschou Nielsen O, Nielsen ML, Gehl J. Traffic-related air pollution: exposure and health effects in Copenhagen street cleaners and cemetery workers. Arch Environ Health 1995; 50:207-13.

9 Sobaszek A, Edme JL, Boulenguez C, et al. Respiratory symptoms and pulmonary function among stainless steel welders. F Occup Environ Med 1998;40:223-9.

10 Bradshaw LM, Fishwick D, Slater T, et al. Chronic bronchitis, work related respiratory symptoms, and pulmonary function in welders in New Zealand. Occup Environ Med 1998;55:150-4.

11 Melbostad E, Eduard W, Magnus P. Chronic bronchitis in farmers. Scand f Work Environ Health 1997;23:271-80.

12 Higgins $M$. Risk factors associated with chronic obstructive lung disease. Ann N Y Acad Sci 1991;624:7-17.

13 Garshick E, Schenker MB, Dosman JA. Occupationally induced airways obstruction. Med Clin North Am 1996;80: 851-78

14 Vestbo J, Hein HO, Suadicani P, et al. Genetic markers for chronic bronchitis and peak expiratory flow in the Copenhagen male study. Dan Med Bull 1993;40:378-80.

15 Gyntelberg F. Physical fitness and coronary heart disease in male residents in Copenhagen aged 40-59. Dan Med Bull 1973;20:1-4.

16 Fletcher CM, Elmes PC, Fairbairn AS, et al. The significance of respiratory symptoms and the diagnoses of chronic bronchitis in a working population. BMF 1959; 257-66.

17 Suadicani P, Hein HO, Gyntelberg F. Serum validated tobacco use and social inequalities in risk of ischaemic heart disease. Int 7 Epidemiol 1994;23:293-300.

18 Rose GA, Holland WW, Crowley EA. A sphygmomanometer for epidemiologists. Lancet 1964;i:296-300.

19 Svalastoga K., Prestige, class and mobility. Copenhagen: Munksgaard, 1959.

20 Hansen EJ. Socialgrupper $i$ Danmark. Copenhagen: The Institute of Danish Social Science,1984. (Study no 48.)

21 Norusis M. SPSS for Windows: Base system users guide, release 6.0. Chicago, Illinois: SPSS, 1994.

22 Norusis M. SPSS for Windows: Advanced statistics, release 6.1. Chicago, Illinois: SPSS, 1994.

23 Hosmer DW, Lemeshow S. Applied logistic regression. New York, USA: Wiley-Interscience, 1989.

24 Kleinbaum DG, Kupper LL, Morgenstern H. Epidemiological research. Principles and quantitative methods. London: Lifetime Learning, 1982

25 Schrijen F, Uffholtz H, Polu JM, et al. Pulmonary and systemic hemodynamic evolution in chronic bronchitis. Am Rev Respir Dis 1978;117:25-31.

$26 \mathrm{La}$ Vecchia C, Decarli A, Negri E, et al. Height and the prevalence of chronic disease. Rev Epidemiol Sante Publique 1992;40:6-14

27 Mourant AE, Kopec AC, Damaniewska-Sobczak K. The distribution of the human blood groups and other polymordistribution of the human blood groups and other

phisms. London: Oxford University Press, 1976 .
28 Suadicani P, Hein HO, Gyntelberg F. Do physical and chemical working conditions explain the association of social class with ischaemic heart disease? Atherosclerosis 1995;113:63.

29 Shephard RJ. Immune changes induced by exercise in an adverse environment. Can F Physiol Pharmacol 1998;76: $539-46$

30 Klein HG. Blood group antigens and antibodies. In: Isselbacher KJ, Braunwald E, Wilson JD, et al, editors. Harrison's principles of internal medicine, 13th ed. New York: McGraw-Hill, 1994:1790.

31 Vineis P, Bartsch $\mathrm{H}$, Caporaso N, et al. Genetically based $\mathrm{N}$-acetyltransferase metabolic polymorphism and low-level environmental exposure to carcinogens. Nature 1994;369: 154-6.

32 Rehm J, Bondy S. Alcohol and all-cause mortality: an overview. Novartis Found Symp 1998;223:223-32.

33 Jousilahti P, Salomaa V, Rasi V, et al. Symptoms of chronic bronchitis, haemostatic factors, and coronary heart disease risk. Atherosclerosis 1999;142:403-7. 